\title{
Cultural influences in cross border cooperation. An overview on Romania - Serbia cross border EU financed programme
}

\author{
Cătălin PLOAE \\ The Bucharest University of Economic Studies, Bucharest, Romania \\ catalin.ploae@rei.ase.ro
}

\begin{abstract}
Since the collapse of the Soviet bloc, European borders have undergone major transformations. Increasing flows of commodities, people, capital, information, and knowledge, coupled with the process of Europeanization, have critically changed the functions and significance of borders (Anderson and O'Dowd 1999, van Houtum 2000, O'Dowd 2003). In this context, we raise the question if culture does have a causal effect on economic development at this level of cross-border cooperation? The data on European regions suggest that it does. This paper focuses on identifying the way culture influence the way countries cooperates within cross border policies and programs in the European area, giving also an overview on particular issues of Cross Border cooperation between Romania and Serbia.
\end{abstract}

Keywords: border, cross-border cooperation, culture, cultural influences.

\section{Introduction}

The focus on the concept of border has a long history and a diverse approach within social sciences, from historical, socio-economic, and anthropological to political perspectives (Cassarino, 2005).

The border can be, in the same time but in different approaches, an area of division and demarcation or an area of contact, exchange and integration: therefore, borders can separate or they can connect. Nowadays, Europe that knows the trends of globalization, the process of integration, the revival of local identities and the growth of regionalism, witnesses also more the phenomenon of open borders (Paasi, 2002), more complex borderlands and multiple approaches on nation-state boundaries.

Within this context, cross-border cooperation within the European Union (EU) and across its external borders has a long story dating back from ' 50 s and has evolved into a variety of forms. It has become a "fingerprint "of the EU integration process and, as such, is supported by EU structural funding and other initiatives (Scott, 2012). Cross-border cooperation remains central to the process of ameliorating ethnonational territorial conflict derived from the distinct lack of fit between modern state borders and ethno-national communities. In this respect, this kind of cooperation is integral to conflict amelioration because it promises to open the territorial framework of the state to enable the development of intercultural dialogue with those on the other side of the border.

The European Union (EU) gradually moved toward a more comprehensive border's policy which added political and security concerns to its earlier focus on cross-border economic cooperation. This shift was facilitated by EU expansion to Eastern Europe in the wake of the collapse of communism, and the increased prominence of intra-state divisions in the Balkan area. Within this context, expanding the free market was followed by a political focus on security threats linked to crime, 
illegal immigration and terrorism, all of which became important issues on EU and Member States agenda (McCall, 2006).

\section{Literature review}

Evidence in different studies reveals the fact that a border may influence the socioeconomic picture of neighboring areas, and has a psychological effect on the attitude of the population alongside the border, including cultural influences.

Borders affect the way in which national policies are framed and accomplished, since their sheer existence affects the mental map and strategic views of political actors (Attila Fabian, 2013).

\section{Borderlands taxonomy and the cultural perspective}

Borderlands are conceptualized as unique spaces at the intersection of two or more cultures with shared characteristics that define them as unique cultural places, considered as zones of transition. Located far from the heartland of a state, external influences on borderlands and their institutions are stronger than in the center of the country. This uniqueness is given by three important features: borderlands are zones of transnational interactions, borderlands are frequently blended zones of crosscultural communication and, finally, borderlands are characterized by separateness from the country's heart (Martinez, 2004).

Baud and Van Schendel (1997) categorized borderlands into three types of spaces based on distance from the border. That would be: the border heartland (dominated by its physical location relative to the border and number of cross-border social networks), the intermediate borderlands (areas on both sides where the influence of the border is moderate to weak) and the outer borderlands (regions on both sides which only under specific circumstances experience interethnic or transnational activities associated with the border).

Oscar Martinez's taxonomy of borderlands evolution reveals their linear evolution from alienated to coexistent, to interdependent and integrated regions, this evolution being based on increasing transnational interactions, which once establish support the evolution towards more integrated cross-border and cross-cultural linkages. As the political relationship between two countries becomes more cooperative, a more favorable climate for economic cooperation develops and once the two economies become more structurally bound to one another, each country gives up part of its sovereignty for improving the mutual progress. In the end, if economic development is similar on the both sides of the border, a new ideology supporting the economic and culturally integrated borderland will develop (Martinez, 1994). A more complex classification is provided by a structure of eleven types of borderlands (Minghi, 2007) including categories such as superimposition and conversion, war and confrontation, transition from conflict to harmony, exclusion and competition. This classification offers no perspective on inherent evolution from one category to the next, borderlands may fall into more than one category reflecting the complexity of the border. 
Nowadays, European borders, though still economically peripheral regions, receive special funding from EU budget to ameliorate the peripheral position by working together with communities across the border.

Borderlands are not only economic geographical areas but also cultural communities, scenes of social contacts perceived by individuals where conflicts arise and where different cultures are in contact without losing their traditions and specific features. Borders are places where different cultures which do not intend to give up their specificity are engaging in interaction. We can identify in this respect a kind of contact zone, a space where the linguistic and cultural interactions of two adjacent cultural areas are extremely strong (Kemenyfi 1994) and cannot be divided into sharply separated units (Barth 1996). Postmodern approaches describe borderlands as temporary zones of up-rooting and reterritorialization which form the identity of people living there (Gupta and Ferguson, 1992). In the contact areas of "we "and "the other person", it can be observed how cross-border cooperation leads to the changing of values connected with identity in the case of those who cross the border physically and thus "terminate" the border (Donnan and Wilson, 1999). We can therefore consider that the cultural landscape of border regions surpasses the political one (Anderson et al., 2003). The outer borders develop their own culture; while we can consider this border as an institution created by society through which people living in borderlands mutually influence each other and which affects the self-perception of people living there, regarding identity, values and interests. These intercultural relations build new feelings of belonging to somewhere where people living along the border make themselves mutually at home. This "multiple personality" of the population living along the border implies that a strategy aiming at multiple identities will be developed, this motivating cross-border projects and involving sub-state participants into the bilateral game with central authorities and external partners (Attila Fabian, 2013).

Yet it is considered that national borders will remain significant factors in transnational communities, because while transnationalism describes borders as places which are now frequently crossed as individuals move beyond the confinements of nation-states, at the same time, nations remain as the crucial means by which people negotiate their identities. In this respect, cross-border integration will create a new layer of identity and not replace existing identities in borderlands (Strüver, 2005).

\section{Typology of borderlands in Europe}

The European Union's enlargement to Central and Eastern Europe has dramatically increased the saliency of the external border question, due to two important reasons.

First it is because the concept of external border as a barrier was inherently challenged by alternative border concepts with the fall of the "Iron Curtain" and the collapse of the Soviet Union. Second is taking into consideration the fact that the unprecedented scope of the complex enlargement of 2004 raised the wider question of the European Union (EU) definitive frontiers, especially within the older West European members. The demand to define the EU's final borders stems from the desire to pinpoint a European identity, particularly in relation to external "other", rather than its internal national, sub-national or even historical one (De Bardeleben, 
2005; Diez, 2004; Strah, 2000). There is also the need to alter the nature of the EU's borders, from acting as frontiers or barriers into being borderlands and borderregions.

In terms of typology, border areas in Europe fall into three important groups: the Western European, the Central European and the Eastern European (Bufon, 1998). The first group consists of the primary borders within the European Union (EU) space (namely the founder States of European Economic Community), which developed parallel to the historical regions in the area. Due to this long experience of cooperation, the area in discussion knew early forms of institutional cross-border cooperation, followed in the same time by the formation of the cross-border regions, known as Euro regions. For the last, one of the main characteristics was the existence of individual administrative units of different rank conjoining into an institutional cross-border interest network. This could be considered as a "region of regions" (Bufon, Markelj, 2010). The second group is related to Central Europe, where historical regions often don't match the actual spatial regionalization of individual states, due to the delimitation processes that took place during the last century. Therefore, we can find somehow a persistence of socio-economic and cultural linkage within border populations in the above mentioned historical regions that led to a spontaneous formation of functional cross-border areas (e.g. Czech Republic and Slovakia, Poland and Eastern Germany); in this respect, we observe the fact that the cross-border regions in this part of Europe don't fit the administrative spaces but rather fits the ancient historical regions (Bufon, Markelj, 2010). Within the third group, that of Eastern Europe, we find a mix of old and new borders in a space often characterized as turbulent, less developed and less populated. Within this area, the communist regimes promoted a very closed and militarized approach toward external borders (as in Romania and Bulgaria). Therefore, even today, with the elimination of the ideological modification influences, there are very limited possibilities of creating more intense forms of cross-border cooperation and integration.

\section{Cross-border regions and cooperation in Europe}

Currently in the European Union (EU) we can identify around 55 institutionalized cross-border regions and about 30 informal cross-border regions (Bufon, 2006).

When referring to the concept of cross-border region, we lay on the definition adopted by the Council of Europe that states that cross-border regions are "characterised by homogenous features and functional interdependencies because otherwise there is no need for cross-border co-operation" (CoE, 1972). Otherwise said, we refer to the fact that "a trans-frontier region is a potential region, inherent in geography, history, ecology, ethnic groups, economic possibilities and so on, but disrupted by the sovereignty of the governments ruling on each side of the frontier" (CoE, 1995).

Cross-border cooperation (CBC) within European Union has a long history and can be studied form various research perspectives, from economic approach to the political science one, passing through anthropology and even geography. Within their efforts of defining cross-border cooperation, the Association of European Border Regions appreciates that "cross-border involves direct neighborly cooperation in all 
areas of life between regional and local authorities along the border and involving all actors" (Martinos, Mahnkopf, 1999).

As our introspection refers to a certain type of cooperation - that between Romania and Serbia - , we shall focus on inventorying the state of art within the institutionalized approach on cross-border cooperation. In this respect, of great importance is to see how social practices influence the institution building across borders, as from the cultural perspective borders are seen to be socially constructed spaces. Cross-border identities and social relations persist notwithstanding the political changes in border demarcations, as borders being never clear-cut (Perkmann, Sum, 2002).

From institutional point of view, three main cross-border institutional structures can be defined: European INTERREG structures (establish at European Commission level); national, regional and supranational entities responsible for INTERREG implementation (e.g. central state agencies or regional authorities that act within the institutional context represented by European Union regulations); and Euro-regions (that have become the standard model of cross-border cooperation: for example, the German/Dutch EUREGIO). This cross-border governance could be explained by appealing the network metaphor (Perkmann, 1999), in the sense of viewing cross-border as part of the EU multi-level institutionalization strategy carried out "in order to facilitate cooperation and the vertical and horizontal coordination of policy between different spatial levels" (Scott, 1999). Within this approach, different entities arise as key actors in the cross-border cooperation, namely: the grass-roots border actors, the INTERREG implementation responsible authorities and the European Commission (Jauhiainen, 1999), otherwise said local entities, national governmental authorities and supranational structures (INTERREG).

Cultural identity is seen as a strong basis for cross-border development, as it could be assumed that cross-border areas with common historical and cultural identity would enjoy more intense cross-border cooperation. As we've already mentioned, the borders acts as a barrier with a protective function separating the "self" from "the other" but it also creates opportunities for cross-border contact providing certain benefits, such as jobs and cultural exchange (Newman, 2003). Therefore, cross-border cooperation is commonly seen as involving multiple identities (national, European and cross-border regional identities) and within this approach it is considered that cross-border institutions might facilitate the deconstruction the old boundaries between the Self and the Other, even if this process is extremely difficult. Basically, considering cross-border cooperation as a development resource we can define it as being based on economic synergy, addressing pragmatic issues, creating a sense of "shared region" and reducing negative mentally and physically border effects.

A important issue when overviewing European Union cross-border cooperation refers to the fact that national institutional contexts on different sides of the border generate administrative and territorial asymmetries, which act as an obstacle for the establishment of more integrated regions. A relatively vast literature investigated the power of both borders and bureaucracy to control, exclude and separate, taking into consideration also the uses and abuses of bureaucracy on borders. Different studies notably investigated the bureaucracy characteristics of being seemingly rational, neutral and objective while in reality being subjective, 
ideological and irrational (e.g., Shore, Wright and Pero, 2009; Strathern, 2000). Crossborder cooperation is therefore challenging because of the divergent administrative or bureaucratic practices and structures.

\section{Overview on Romania and Serbia cross-border region and CBC}

The cross-border cooperation region between Romania and Serbia was established in PICBE | 621 2007 and is defined within the framework of the Romania-Serbia IPA CBC Programme that is designed in the framework of the European strategy for a smart inclusive and sustainable growth.

The Programme Area partially overlaps (e.g. CBC Hungary-Serbia) or is contained (e.g. South East Europe or the future Danube Programme) to a number of other Territorial Cooperation Programmes. Many of these Programmes follow similar objectives and have relevant thematic orientations. In the same time a number of euro regions are active in the area, the most important being the "Danube-Kris-Mureș-Tisa Regional Cooperation" (DKMT) established in 1997 with the aim to develop and broaden relationships among local communities and local governments in the field of economy, education, culture, science and sports - and help the region to maintain the process of the European integration. The programme area is at the center of the European Danube Macro Region. The two partner countries include a large share of the river basin, their total surface representing 10\% of the basin in Serbia and 29\% in Romania. The total area is $40.596 \mathrm{~km}^{2}$ (53, $1 \%$ in Romania/ 46, 9\% in Serbia), including three counties of Romania, and the six districts of Serbia. The length of the border in the eligible territories between Romania and Republic of Serbia is $546 \mathrm{~km}$, out of which $290 \mathrm{~km}$ (53.1\%) on the Danube River. The length of the border in the programme area represents $26 \%$ of the external borders of Serbia, and $17 \%$ of the external borders of Romania. Along this common border there are five constantly operating road border crossings and 2 constantly operating railroad crossings. Also, there are 6 fluvial ports in Serbia and 3 on the Romanian shore.

In terms of strategic planning within EU policies framework, in the Partnership Agreement between Romania and European Commission, it is assumed that CBC programs should emphasize the importance of promoting employment, improving tourism and promoting cultural heritage while enhancing the connection between the communities of the border areas. Improvement of the transport and environmental system is also promoted. Romania is committed to remove the existing bottlenecks concerning the cross-border transport flows and to strengthen cooperation especially in the energy sector, in order to raise energy efficiency, decrease pollution and to widen the production, distribution and consumption of renewable energy sources. In the same time, according to the National Plan for the Adoption of the Acquis - NPAA (2014-2018), the Republic of Serbia is highly motivated to develop relations with immediate neighbours and countries in the region of South-East Europe, thus affirming one of the priorities of its foreign policy - improvement of regional cooperation. In the strategy of Serbia, regional cooperation, especially through regional fora and initiatives, although not replacing the process of integration to the EU, represents a central contribution to strengthening of bilateral relations with the neighbours and the states from the South - East Europe region. 
First experience for the two countries institutionalized cross-border cooperation concluded through the Romania-Serbia CBC Programme for 2007-2013 periods. According to the survey carried out during this Programme evaluation exercise, the programme stakeholders considered the strategy too broadly defined, lacking of focus on specific development priorities for the area. Programme Stakeholders pointed out the need of stronger coordination with the central administrative level in each country and with the Management Authorities of other IPA Programmes covering overlapping eligible regions (Romania - Serbia, Hungary Serbia and Bulgaria - Serbia) and with the European macro-regional strategies relevant to the cross-border area (Evaluation Report Romania-Republic of Serbia Programme 2012).

Following the assessment of the first Cross Border Cooperation programme, the main potentials of action in the cross-border region have been identified in the fields of inclusive growth, environment protection, SMART innovation, accessibility and renewable energy. In all the above-mentioned fields, challenges and opportunities have been identified especially when considering the main exogenous driving factors, like the global environmental changes, the international tourism markets and the integration of the global economy. Most of these areas can aim to a synergic interaction with the European strategy for the Danube Macro-region. According to the results of the analysis and the identified needs and challenges, and based on the lesson learned from the previous programme, four priorities have been established for 2014-2020 programming period: employment promotion and basic services strengthening for an inclusive growth; environmental protection and risk management; sustainable mobility and accessibility; attractiveness for sustainable.

\section{Conclusion}

Following a European Commission's online public consultation conducted by DGRegio in 2015, data revealed that language barriers and difficult physical access are frequently mentioned as obstacles.

The very high relevance of barriers to physical access in this survey confirms that the work on cross-border mobility is a must in border regions, and that priorities should be better adapted to the specific needs of these regions. Also, the obstacles faced by border regions often originate from a lack of understanding of neighbouring languages, hampering access to information, as well as an inadequate general sociocultural knowledge of the neighbouring society. On the other hand, the relatively rare mention of lack of trust as an obstacle in border regions is reassuring in the sense that it indicates that there is a good basis for border regions to continue to make progress in cooperation. The fact that trust, as well as sociocultural differences and language barriers, are even less of a problem for those who cross the border more frequently is particularly encouraging. This approach fosters the solution for a perceived lack of trust and socio-cultural differences to be the engagement in cultural and language exchange projects.

In conclusion, we appreciate that, in order to give a boost to cross-border cooperation, including the Romania - Serbia CBC programme, for all regions in Europe 
to benefit from these proven positive effects of this process, some actions are needed to be taken:

- The higher involvement of civil society at local and regional level in decision-making planning;

- The development of more decisive and targeted support mechanism;

- EU's external impact needs reinforcement through greater socio-cultural engagement.

In terms of policy design, we appreciate that some options could be taken into consideration:

- $\quad$ Creating more specific incentives for CBC;

- $\quad$ Targeting civil society and fostering its participation in CBC;

- Integrating local knowledge in understanding the CBC's role for Regional Development.

\section{References}

Anderson, J., O’Dowd, L., Wilson, T. M. (2003). New borders for a changing Europe: cross-border cooperation and governance, London, Frank Cass Strüver.

Attila F. (2013). Constructivist Views of Cooperation along the Border, Acta Univ. Sapientiae, Economics and Business, 1(1), 39-51.

Baud, M., Van Schendel, W. (1997). Toward a Comparative History of Borderlands, Journal of World History, 8 (2), 211-242.

Bufon, M., (2006). Between social and spatial convergence and divergence: an exploration into the political geography of European contact areas. GeoJournal 66(4), 341-352.

Bufon, M., Markelj, V. (2010). Regional Policies and Cross-Border Cooperation: New Challenges and New Development Models in Central Europe, Revista Româna de Geografie Politica, 12 (1), 18-28.

Cassarino,J.P., (2005). Approaching borders and Frontiers: Notions and implications, Florence, European University Institute.

Council of Europe - CoE (1972). 1. Europäisches Symposium der Grenzregionen. Die Zusammenarbeit europäischer Grenzgebiete. Strasbourg: Council of Europe.

Council of Europe - CoE (1995). Manuel de coopération transfrontaliére à l'usage des collectivités locales et régionales en Europe. Strasbourg: Council of Europe.

Diez, T. (2004). Europe's Other and the return of Geopolitics, Cambridge Review of International Affairs, 17(2), 319-335.

Donnan, H., Wilson, T. (1999). Borders: Frontiers of Identity, Nation \& State, Oxford \& New York, Berg;

Gupta, A., Ferguson, J. (1992). Beyond"Culture": Space, Identity, and the Politics of Difference, Cultural Anthropology, 7(1), 6-23.

Jauhiainen, J. (2002). Territoriality and Topocracy of Cross-Border Networks, Journal of Baltic Studies, 33(2).

Martinez, O. (1994). Border People: Life and Society in the U.S.-Mexico Borderlands, University of Arizona Press: Tucson, Arizona. 
Martinos, H., Mahnkopf, K. (1999). Institutional Aspects of Cross-Border Cooperation, A report carried out by the Association of European Border Regions as part of the LACE-TAP Project.

McCall, C. (2006). Creating border space: an EU approach to ethno-national security, Belfast: Centre for International Borders Research, Working Paper Series.

Minghi, J. (2007). Borderscapes: A Tentative Classification, Paper presented at the

PICBE $\mid 624$ annual meeting of the American Association of Geographers, San Francisco.

Newman, D. (2003). On Borders and Power: A Theoretical Framework, Journal of Borderland Studies, 18(1), 13-25.

Paasi, A. (2002). Place, Boundaries and the Construction of Territory, in Boundaries and Place: European borderlands in Geographical Context (eds.). David Kaplan, Jouni Hälki, Rowman and Littlefield Publishers: Oxford, England, 178-199.

Perkmann, M. (1999). Building Governance Institutions Across European Borders, Regional Studies, 33(7)

Perkmann, M., Sum, N. (2002). Globalization, regionalization and cross-border regions: scales, discourses and governance, In Perkmann, M. and Sum, N. (Eds.) Globalization, Regionalization and Cross-Border Regions, 3-21, Palgrave Macmillan: Houndmills;

Shore, C., Wright, S., Pero, D. (2009). Policy Worlds: Anthropology and the Anatomy of Contemporary Power, London, UK: Berghahn.

Strathern, M. (ed). (2000). Audit Cultures: Anthropological Studies in Accountability, Ethics and the Academy. New York: Routledge. 